\title{
Infrared Absorption Spectra of Seven Cyclopentanes and Five Cyclohexanes
}

\author{
By Earle K. Plyler, Ralph Stair, and Curtis J. Humphreys
}

\begin{abstract}
The infrared absorption spectra of seven cyclopentanes and five cyclohexanes have been measured in the region from 2 to 15 microns. The substances were cyclopentane, methylcyclopentane, 1,1-dimethylcyclopentane, trans-1,2-dimethylcyclopentane, trans-1, 3-dimethylcyclopentane, cis-1,2-dimethylcyclopentane, and cis, trans, cis-1,2,4-trimethylcyclopentane, also cyclohexane, methylcyclohexane, 1,1-dimethylcyclohexane, trans-1,2dimethylcyclohexane, and cis-1,2-dimethylcyclohexane. The wavelengths of all the observed absorption bands are given in a table, and a graph is shown of the percentage transmission over the wavelength region of each substance. The hydrocarbons were highly purified in the Chemistry Division and these spectra will be of value as a check on the purity of these compounds which may be obtained from other sources. Also the more intense bands serve as a means of identification. For each substance the bands that are best suited for distinguishing it are noted.

Of special interest are the four dimethylcyclopentanes which were studied. The structural positions of the substituted methyl groups differ only slightly, but the spectral difference is quite marked. The infrared absorption spectra are well suited to show characteristic differences between isomers.

The measurements were made with a Perkin-Elmer spectrometer with a General Motors amplifier and Brown recorder. A slit control mechanism is described in detail. Although the slit control gear arrangement is relatively simple, the results obtained with it are good. The energy output is held nearly constant from 3.5 to 14.5 microns.
\end{abstract}

\section{Introduction}

In the Bureau's cooperative research program with the American Petroleum Institute, many of the constituents of petroleum have been purified to a high degree. Various physical and chemical properties of these constituents are being investigated. The Radiometry Section of the Bureau is contributing to this program by measuring the infrared absorption spectra of a number of these compounds. This report deals with two series of compounds, cyclopentanes and cyclohexanes, that are closely related and which show some interesting properties. The absorption spectra of 1,1dimethylcyclopentane, cis-1,2-dimethylcyclopentane, cis, trans, cis-1,2,4-trimethylcyclopentane, and 1,1-dimethylcyclohexane have not been previously measured.

\section{Method of Measurement}

A Perkin-Elmer model $12 \mathrm{~A}$ infrared spectrometer with an $\mathrm{NaCl}$ prism was used as the dispersing instrument. The prism face is 60 by 75 
$\mathrm{mm}$ and an off-axis mirror of $27 \mathrm{~cm}$ focal length is used as the collimator. More details about the instrument can be found in the article "Small prism infrared spectrometry" [1]. ${ }^{1}$ It was found that better resolution of the water-vapor band at $6.26 \mu$ was obtained when the slits were reduced from 0.05 to $0.02 \mathrm{~mm}$. This demonstrated the high quality of the optical parts.

When the instrument was obtained from the manufacturer, there was no provision for the automatic rotation of the wavelength drum or the slit drum. In order to measure the region from $2 \mu$ to $15 \mu$ continuously, a synchronous motor with gear reduction was connected to the wavelength drum. The selection of gears made it possible to traverse this region of the spectrum in 45 or 90 minutes. A globar element was used for the source, and for a fixed slit width the maximum radiation was found to occur in the region of $2 \mu$. When the drum was set for wavelengths greater than $2 \mu$, the deflection decreased. In order to keep the deflections approximately constant, it was necessary to open the slits for longer wavelength settings. A graph was plotted of the slit widths required to produce constant energy at various wavelengths. The relationship is not linear, but it was found that three chords closely approximated the curve. The aim of constantenergy output could almost be attained by opening the slits with three different constant speeds. A synchronous motor was used with gears of such ratios that the slits could be opened at the appropriate speeds. Also, a gear shift was installed so that the speed could be changed without stopping the instrument.

With this arrangement, the energy curve is of about the same height above the zero from $3.5 \mu$ to $14 \mu$. There are some regions of the spectrum where the energy drops by a few percent. Somewhat better results could be obtained if, in addition to the slit change, the impedance of the output circuit of the amplifier was varied. Variation of the amplifier gain would not be a satisfactory method of control as the energy of the radiating source at $2 \mu$ is many times greater than the energy at $14 \mu$.

Figure 1 shows the slit control mechanism. The letters identify the different parts. The gears have the following number of teeth: $A, 84 ; B$,

${ }_{1}$ Numbers in brackets indicate the literature references at the end of this paper.

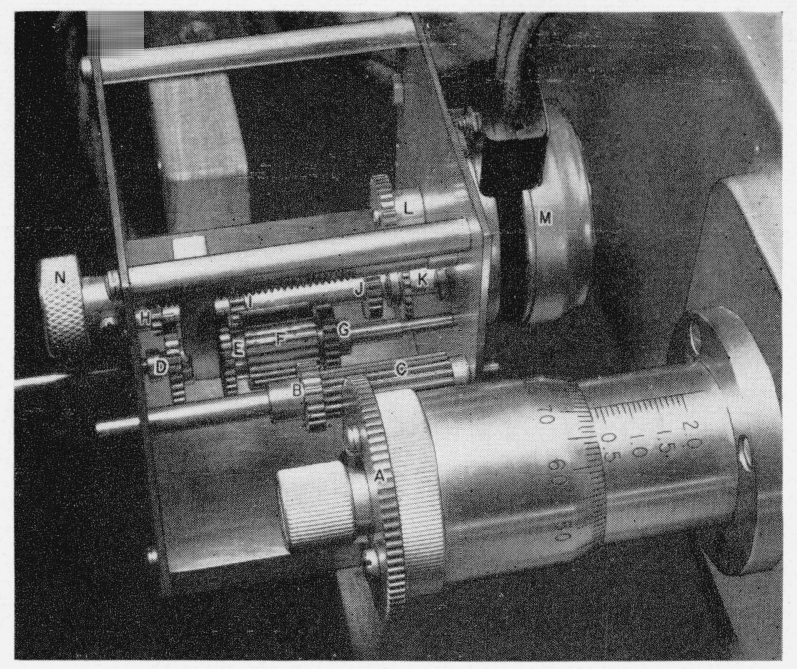

FIgURE 1.-Slit-control mechanism, showing gears and arrangement.

$24 ; C, 18$ (11/8-in-length rod); $D, 36 ; E, 32 ; F$, $28(5 / 8$-in-length rod); $G, 24 ; H, 12 ; I, 16 ; J, 24$; $K, 38 ; L, 32 ; M$, motor $2 \mathrm{rpm} ; N$, gear shift. The gears are standard Boston gears and the rod-gears have the same size teeth.

The ordinary operating conditions are the globar at 50 volts, the General Motors amplifier [2] gain dial at 2.5, wavelength drum traversed in 45 minutes. The slit micrometer is set at $0.019 \mathrm{~mm}$ at $2 \mu$. The wavelength drum is operated to $3 \mu$ without engaging the gears. From 3 to $9 \mu$, the low gear, $H$, is used. From 9 to $12 \mu$, gear $I$ is used, and from 12 to $15 \mu$, gear $J$ is engaged. For different scanning speeds, different gear ratios would be needed. Other features are to be added to the device, such as an automatic stop and a reversing gear for the near infrared region.

The thermocouple is in a housing with a $\mathrm{KBr}$ window, and it is kept at pressure below $10^{-4} \mathrm{~mm}$. The pressure is kept low over long periods of time by means of activated charcoal, and pumping is necessary only every 3 or 4 weeks. The thermocouple approaches its final output in about $1 \frac{1 / 2}{2}$ seconds after it is exposed to radiation. It is connected to a General Motors amplifier that operates a Brown recorder. A smooth tracing is obtained when the amplifier is not operated on too high gains. Under ordinary operating conditions, 1 microvolt produces a full-scale deflection, and the noise level is less than one-fourth of 1 percent of the full scale. The thermocouple contains a 
compensating junction, but this does not completely eliminate the drift. The room temperature is controlled, which is of great help in stabilizing the thermocouple. No change is observed in the zero owing to the opening of the slits, until they become one-half of a millimeter in width. For this and larger openings the zero drift may be considerable.

Under average operating conditions the widths of frequency bands resolved are $16.4 \mathrm{~cm}^{-1}$ at $3.0 \mu$, $5.4 \mathrm{~cm}^{-1}$ at $6.4 \mu, 2.4 \mathrm{~cm}^{-1}$ at $11 \mu$, and $3.5 \mathrm{~cm}^{-1}$ at $14.3 \mu$. In the region beyond $5 \mu$ the wavelength of sharp bands can be repeated to $0.01 \mu$. The instrument is practically free of stray radiation between 2 and $12 \mu$. At $14.5 \mu$ the stray radiation produces about 10 percent of the total deflection.

In the measurement of the absorption of the compounds, two cell thicknesses were used, 0.05 $\mathrm{mm}$ and $0.4 \mathrm{~mm}$, the thicker cell being used to check weak bands. Even with the 0.05-mm cell, the absorption was 100 percent in the region of $3.4 \mu$. As some of the liquids under investigation have high vapor pressures at room temperature, it is necessary to use an enclosed cell. The cell was made by using two plates of rock salt, and separating them by a lead shim $0.05 \mathrm{~mm}$ in thickness. In one of the rock-salt plates two holes were drilled. This allowed the cell to be filled after it was assembled and placed in a metal holder. The shim was cut out so that the radiation passed through the cell and so that the cell could be filled through the holes in the rock-salt plate. The samples of the materials were in the liquid state, and a small amount was drawn from the container into a medicine dropper, from which the liquid was slowly passed into the cell. At the same time a small tube, connected to the reduced-pressure system, was placed in the other hole of the rock-salt plate, and the liquid was drawn into the cell, completely filling it without bubbles. This method of filling was used in rinsing out the cell, when changing from one liquid to another.

The arbitrary numbers of the wavelength drum were calibrated into wave numbers by observing the settings corresponding to known lines and absorption bands. Lines of cadmium [3] and mercury [4] were used for the visible and near infrared region. The absorption bands of water vapor [5] and carbon dioxide gas [6] occurring as atmosphere constituents were used for calibration of the longer wavelengths. The absorption spectra of ammonia gas [7] and methyl alcohol vapor [8] also were measured by the use of a gas cell. In this way, a fairly large number of calibration points distributed throughout the spectrum was obtained.

The spectrometer is partially enclosed and a drying agent is kept in both the prism and source compartments. This reduces the water-vapor absorption. The complete removal of the watervapor absorption spectrum requires an enclosed instrument that may be evacuated or filled with dry gas. However, the absorption bands produced by water vapor and carbon dioxide serve the purpose of a constant check on wavelength calibration and the resolution of the instrument.

Figure 2 shows the trace obtained on the Brown recorder of the $6.26 \mu$ absorption band due to water vapor in the atmosphere in the region from $4 \mu$ to $7 \mu$. The upper curve was obtained by using slits of $0.05 \mathrm{~mm}$ at the shorter wavelength end of the spectrum, and opening them with the automatic slit drive. The amount of energy in the transparent regions between the absorption lines is about constant, and the absorption curve as recorded appears similar to a graph which has the percentage transmission plotted as a function of wavelength. The lower trace in figure 2 is for the water-vapor band with the slits at $0.02 \mathrm{~mm}$ at the shorter wavelength side. It is readily seen that the resolving power has increased with the nar-

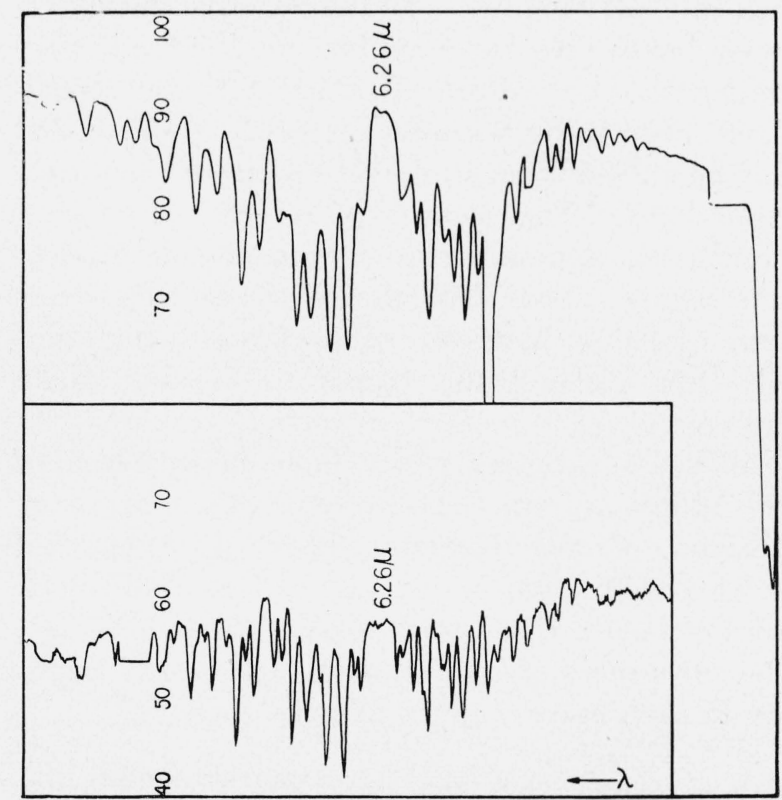

Figure 2.-Two traces for the water-vapor band at $6.26 \mu$ observed with different slit widths. 
rower slits. On each side of the center of the band at $6.26 \mu$ there is seen one line in the upper curve of figure 2. In the lower curve each of these lines has been separated into two. A comparison of other regions of the spectrum will show that additional lines have been revealed by the higher resolution.

The percentage transmission for the different materials was calculated from the recorded energy curve. At first the absorption spectrum of the substance was obtained by placing the filled cell in front of the entrance slit of the spectrometer. The spectrometer drum was connected to the synchronous motor, and a trace of the region from 2 to $15 \mu$ was obtained without removing the cell or using the shutter. This curve showed the wavelength drum readings of the absorption bands. Then a second trace was obtained, and at selected points, in the regions between the absorption bands, the cell was temporarily removed to obtain fullenergy values, and similarly, at other convenient points, the shutter was inserted to determine the zero reading. A line was drawn connecting the full-energy values on the trace, and similarly, another was drawn connecting the zero readings. From these two lines and the energy trace with the cell in place, the percentage absorption could be calculated for any point in the spectrum. A correction was made for the radiation loss due to the rock-salt cell windows. In the region of the watervapor bands, the readings for the filled cell were compared with values obtained for the atmospheric absorption without the cell. Weak bands may be missed because of overlapping of the watervapor lines. This same type of error is encountered in the region of the carbon-dioxide absorption bands. This difficulty was partially overcome by using thick cells of the liquid being studied, thus causing the bands to become much stronger.

All the substances which have been measured were obtained from F. D. Rossini of the Chemistry Division of the Bureau. They were purified under his direction in connection with the American Petroleum Institute Research Project No. 44. The substances studied and the amount of impurity in each one are given in table 1 [9].
TABLE 1.-Purity of compounds

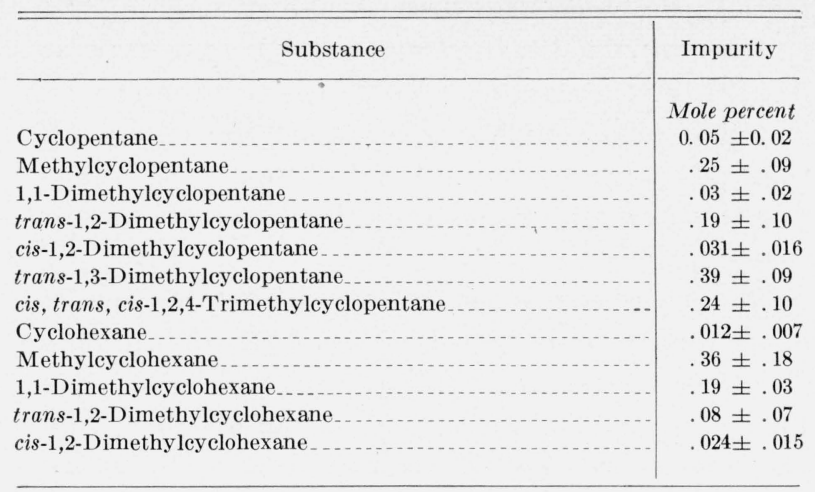

\section{Results and Discussion}

Figure 3 shows the percentage transmission of cyclopentane. For a cell thickness of $0.05 \mathrm{~mm}$ only four intense bands are observed. The wavelengths of the bands and their frequencies are given in table 2 . The coefficients of absorption have not been calculated for these bands. However, the 12 compounds have been measured with the same cell thickness, and the relative intensity of absorption of any band of one compound will be directly comparable with that of any band of any of the other 11 compounds. The band at $3.4 \mu$ is very intense, which arises from the $\mathrm{CH}$ stretching vibrations. As all these materials contain several $\mathrm{CH}$ bonds, this band will be intense in each spectrum. The intense absorption at $3.4 \mu$ is made up of several bands. With cells of the order of $0.004 \mathrm{~mm}$ in thickness the separate bands can be observed. The absorption spectrum in this region was measured with thin cells for cis, trans, cis-1,2, 4-trimethylcyclopentane, cyclohexane, trans-1,2-dimethylcyclohexane and methylcyclohexane. Each substance shows two or three minima of transmission in the region of $3.4 \mu$ when a cell of effective thickness $0.004 \mathrm{~mm}$ was used. The thin absorption layers were obtained by diluting these two hydrocarbons with $\mathrm{CCl}_{4}$ in a cell of $0.05 \mathrm{~mm}$ in thickness. When the cell contained only $\mathrm{CCl}_{4}$, no absorption bands were observed so the entire absorption observed in the mixtures containing the hydrocarbons was attributed to them. The rock-salt prism is not well suited for measurements in this region as its 


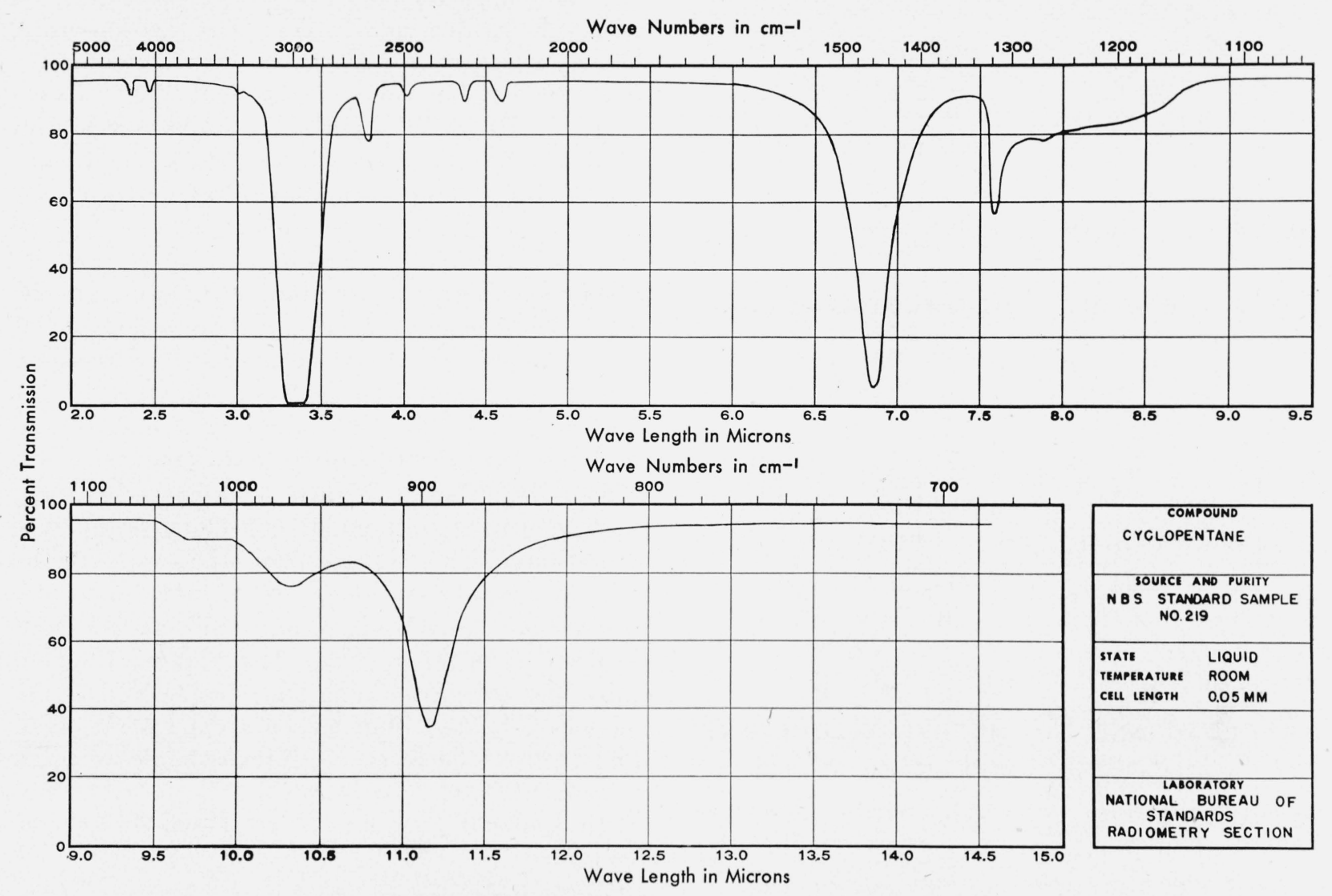

Figure 3.-Percentage transmission of cyclopentane.

dispersion is low. With a grating or a lithium fluoride prism the bands could have been observed with better detail. The strong band at $6.86 \mu$ arises from the $\mathrm{CH}$ bending motion. The intensities of the 3.4 and $6.86 \mu$ bands vary from one substance to the next but the positions remain almost constant for the cyclopentane and the cyclohexane compounds.

The number of fundamental vibrations for a molecule of $n$ atoms is $3 n-6$. For cyclopentane there would be 39 fundamental bands. In addition to these bands there are possibly many combination and harmonic bands, so that the total number of absorption bands could be 200 to 300 . However, the observed spectrum does not show such a large number of absorption bands. The reduced number of bands in the observed spectrum may be due to the fact that a number of the bands are located in the region beyond $15 \mu$ and that the symmetry properties reduce the number of vibrations which would be active in the infrared absorption.
The structure of the cyclopentane molecule and also that of methylcyclopentane are illustrated in figure 4. A study of the various chemical and physical properties has not yet made it possible to decide if all the carbon atoms are in the same plane. If they are coplanar, a high degree of symmetry would be present. When methyl groups are substituted for the hydrogen atoms, there are a number of new compounds formed. If two methyl groups are substituted on the same side of the carbon plane the configuration is called cis and if on opposite sides it is called trans. By substituting methyl groups at various positions of the molecule several isomers may be formed.

A distinguishing feature of the absorption spectrum of cyclopentane is the presence of two intense bands at 7.6 and $11.2 \mu$, that occur in addition to the two regions of absorption due to $\mathrm{CH}$ vibrations. When substitutions are made in the cyclopentane molecule these bands change in position and intensity. 


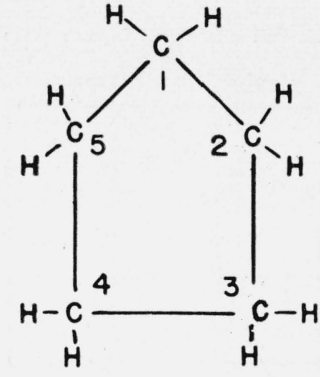

CYCLOPENTANE

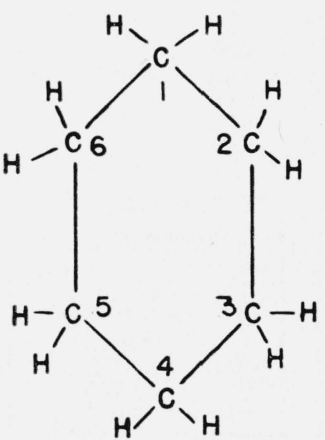

CYCLOHEXANE

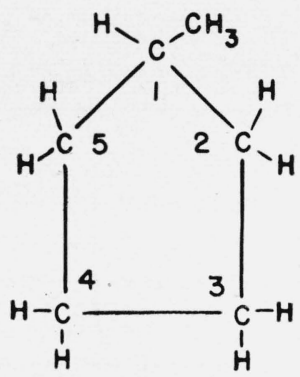

METHYLCYCLOPENTANE

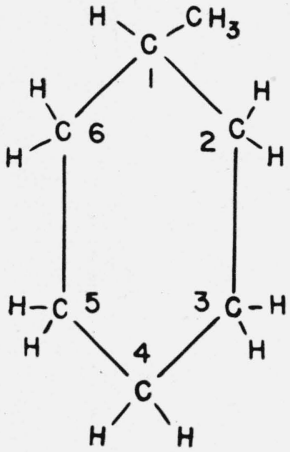

METHYLCYCLOHEXANE

FIgURE 4.- Structural diagram of cyclopertanes and cyclohexanes.

Any possible displacements of the carbon atoms from the coplanar arrange ment are not indicated.
In table 2 all the bands that have been observed for cyclopentane are listed. The low intensity bands occurring in the region from 2 to $5 \mu$ are probably combinations of bands of longer wavelengths. Besides the $\mathrm{CH}$ vibrations there are no elements in the molecule which have fundamental vibrations occurring at wavelengths shorter than $5 \mu$.

The absorption spectrum of methylcyclopentane is shown in figure 5. The substitution of a methyl group has considerably changed the spectrum of cyclopentane. There is a strong band in the region of $7.26 \mu$, which arises from the presence of the methyl group. Any vibration of a part of the molecule is a vibration of the entire molecule, but some groups that are tightly bound together may, with good approximation, be considered as separate vibrations. This appears to be the case with the $\mathrm{CH}_{3}$ group. In the spectrum of other molecules containing the methyl group, an absorption band is observed in this region. Also, methylcyclopentane does not have strong bands at 7.6 and $11.16 \mu$ as in cyclopentane, but has bands at 7.4, 8.8, 10.2, and $11.25 \mu$. There are no intense bands between 11.5 and $14.5 \mu$.

In figures $6,7,8$, and 9 are shown the spectra

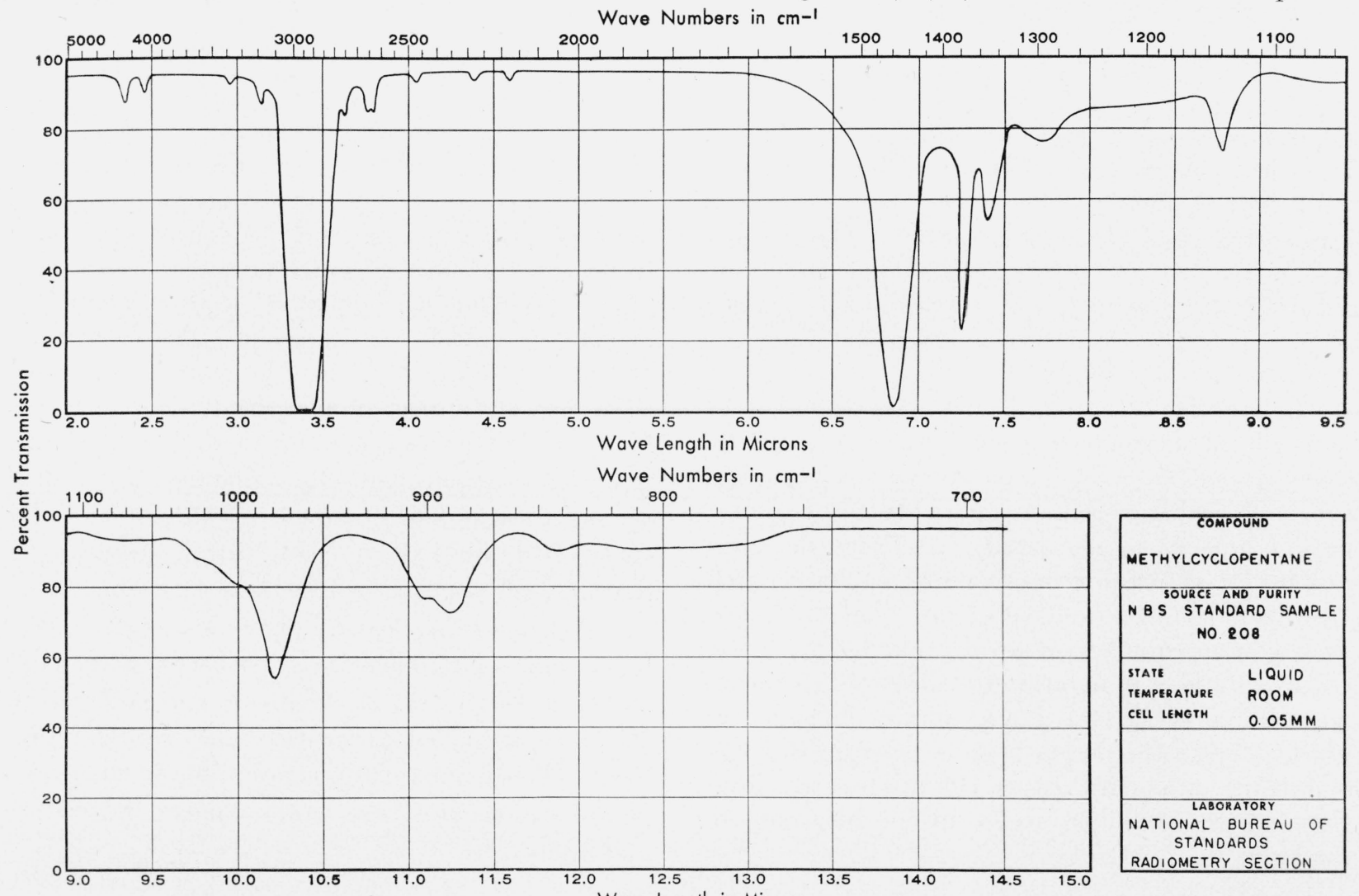


of the four dimethylcyclopentanes, 1,1-dimethylcyclopentane, cis-1, 2-dimethylcyclopentane, trans1,2-dimethylcyclopentane, and trans-1,3-dimethylcyclopentane. The $7.3 \mu$ band varies very little in wavelength, but the intensity has increased when compared with methylcyclopentane. The greater intensity is due to the presence of two methyl groups in each molecule. In the case of the 1,1dimethylcyclopentane the absorption in this region shows two maxima. In the region between 7.5 and $11.5 \mu$ there is a considerable difference between the spectra of these four isomers. Any one of the group could readily be identified by a study of the spectra in this region. This is a good example of the application of infrared absorption spectra to the problem of identifying isomers. The wavelengths of the absorption bands of the four dimethylcyclopentanes are given in table 20 .

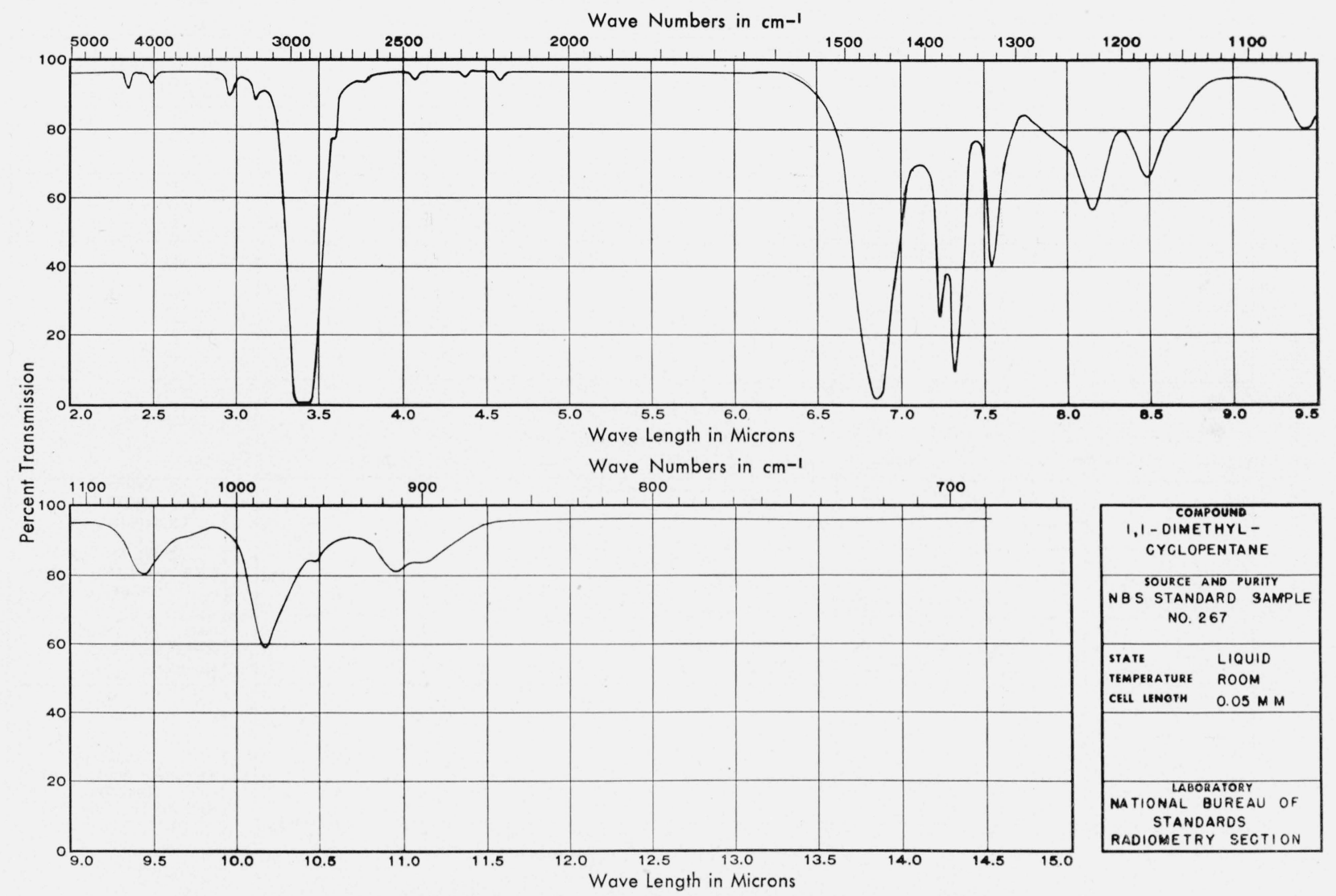

FiguRE 6.-Percentage transmission of 1,1-dimethylcyclopentane. 


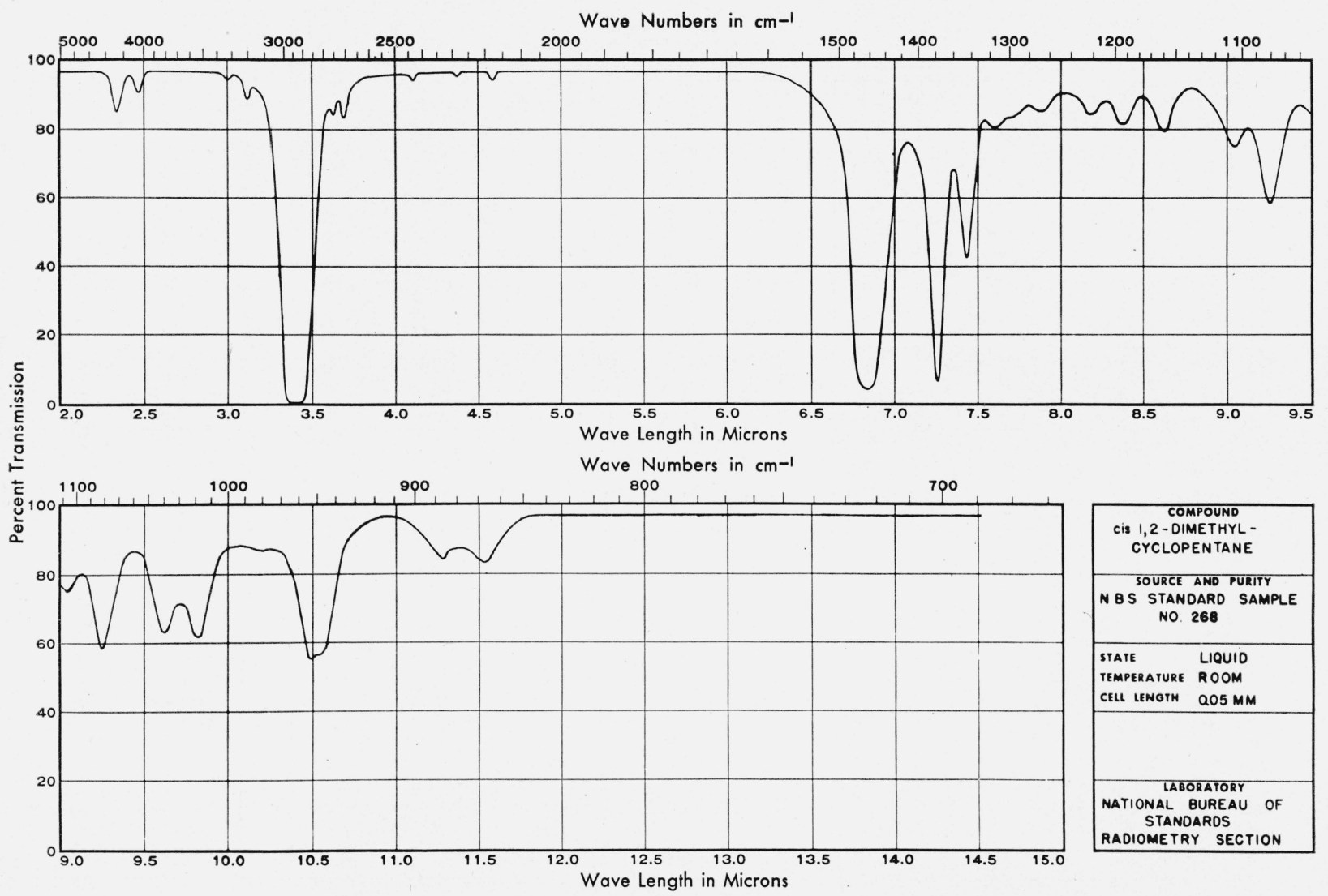

FIGURE 7.-Percentage transmission of cis-1,2-dimethylcyclopentane. 


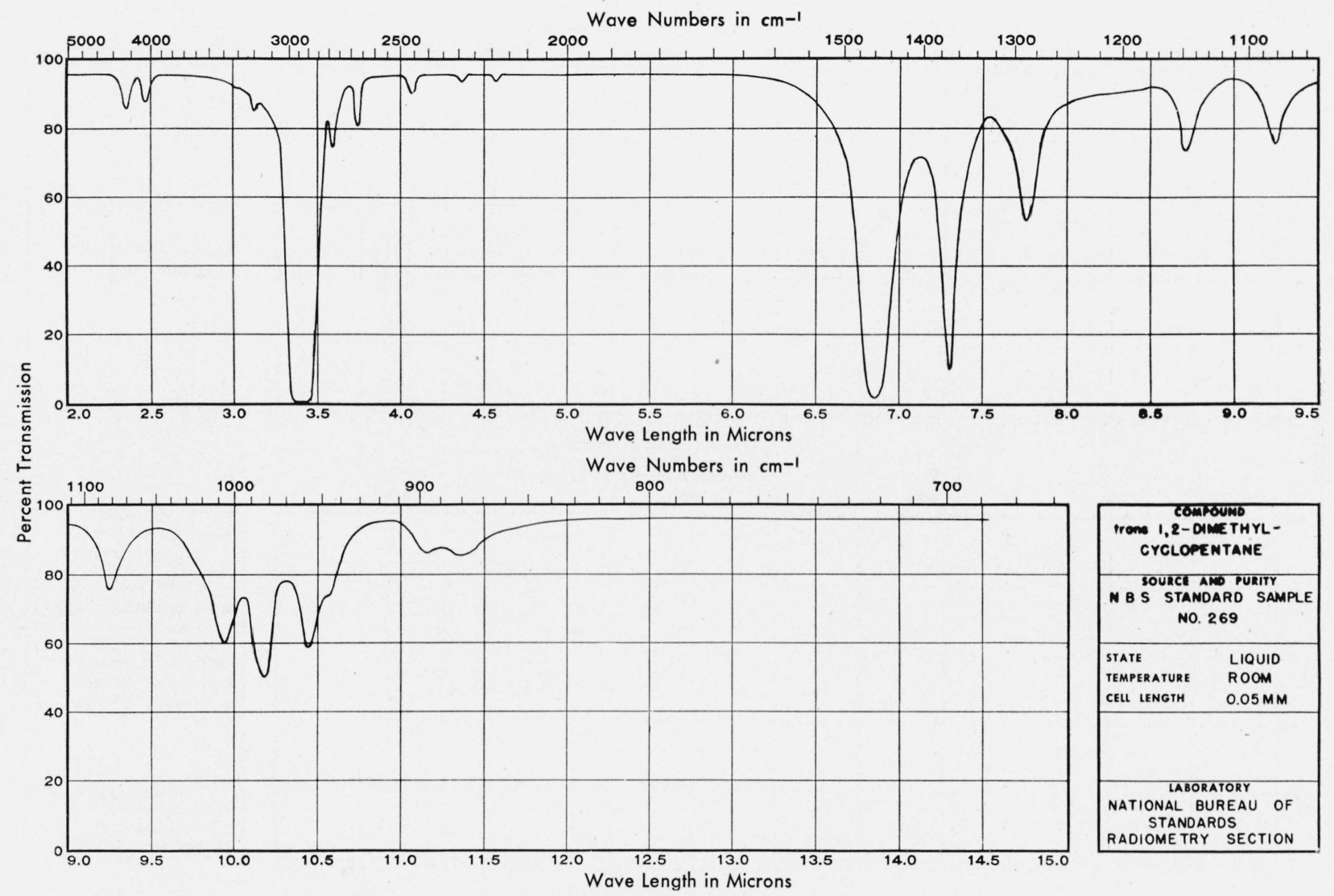

Figure 8.-Percentage transmission of trans-1,2-dimethylcyclopentane. 


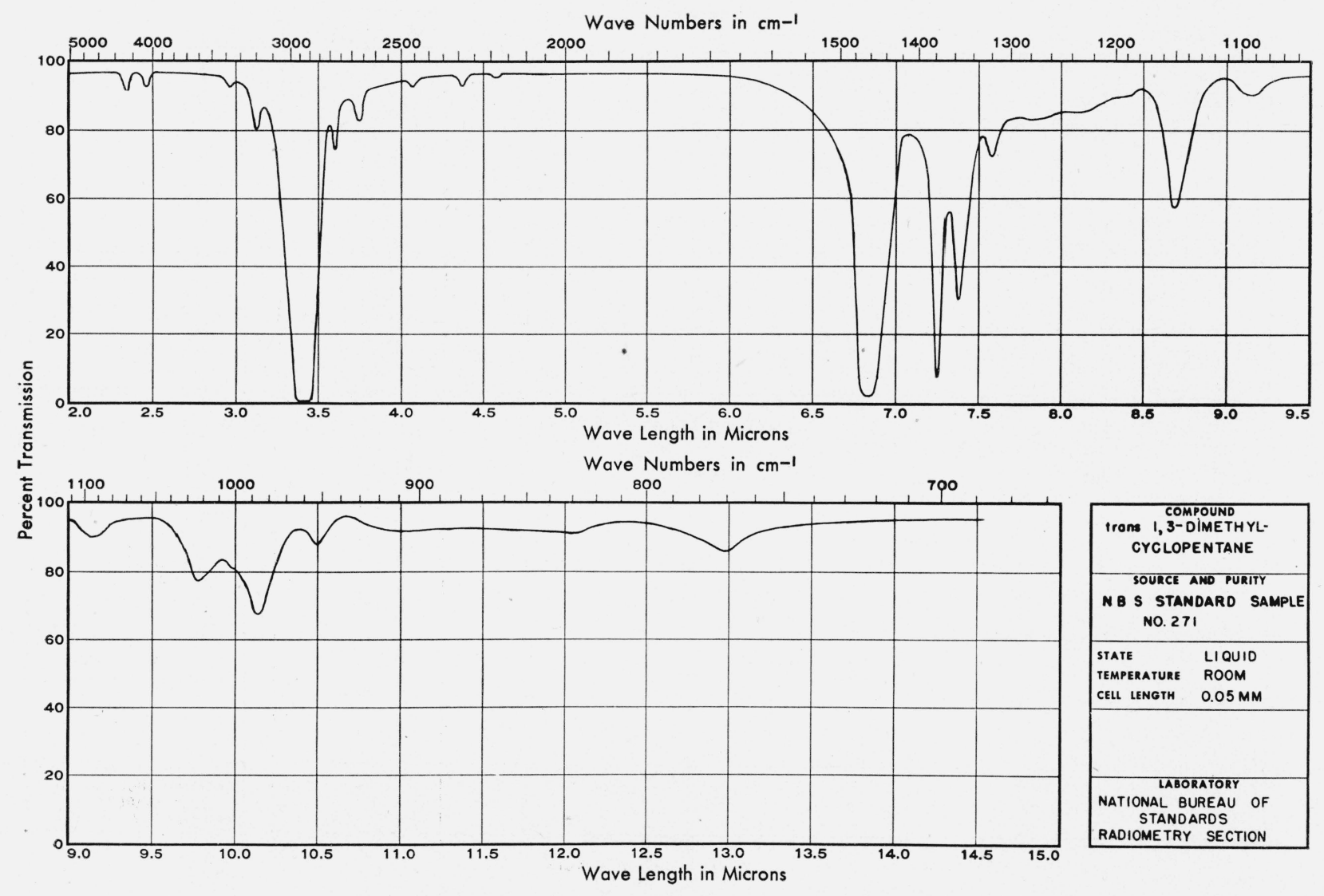

FiguRe 9.-Percentage transmission of trans-1,3-dimethylcyclopentane. 
TABLE 2.-Location of infrared absorption bands

\begin{tabular}{|c|c|c|c|}
\hline $\begin{array}{l}\text { Wave- } \\
\text { length }\end{array}$ & Frequency & $\begin{array}{l}\text { Wave- } \\
\text { length }\end{array}$ & Frequency \\
\hline \multicolumn{4}{|c|}{ CYCLOPENTANE } \\
\hline Microns & $\mathrm{cm}^{-1}$ & Microns & $\mathrm{cm}^{-1}$ \\
\hline 2.34 & 4274 & 4.37 & 2288 \\
\hline 2.46 & 4065 & 4.59 & 2179 \\
\hline 3.01 & 3322 & 6.85 & 1460 \\
\hline 3.38 & 2959 & 7.59 & 1318 \\
\hline 3.78 & 2646 & 7.88 & 1269 \\
\hline 4.02 & 2488 & 10.31 & 970 \\
\hline -...- & $\cdots$ & 11.16 & 896 \\
\hline \multicolumn{4}{|c|}{ METHYLCYCLOPENTANE } \\
\hline 2.34 & 4274 & 4. 59 & 2179 \\
\hline 2.46 & 4065 & 6.86 & 1458 \\
\hline 2.96 & 3378 & 7.26 & 1377 \\
\hline 3.14 & 3185 & 7.40 & 1351 \\
\hline 3.43 & 2915 & 7.72 & 1295 \\
\hline 3. 63 & 2755 & 8.78 & 1139 \\
\hline 3.76 & 2660 & 10.21 & 979 \\
\hline 3.80 & 2632 & 11.09 & 902 \\
\hline 4.05 & 2469 & 11.25 & 889 \\
\hline 4. 39 & 2278 & 11.87 & 842 \\
\hline \multicolumn{4}{|c|}{ 1,1-DIMETHYLCYCLOPENTANE } \\
\hline 2.34 & 4274 & 6.85 & 1460 \\
\hline 2.48 & 4032 & 7. 23 & 1383 \\
\hline 2. 96 & 3378 & 7.32 & 1366 \\
\hline 3.12 & 3205 & 7.54 & 1326 \\
\hline 3.41 & 2933 & 8.15 & 1227 \\
\hline 3.59 & 2786 & 8.48 & 1179 \\
\hline 3. 77 & 2653 & 9.43 & 1060 \\
\hline 4. 07 & 2457 & 10.17 & 983 \\
\hline 4.37 & 2288 & 10.47 & 955 \\
\hline 4.59 & 2179 & 10.95 & 913 \\
\hline$-\cdots$ & -... & 11.13 & 898 \\
\hline \multicolumn{4}{|c|}{ cis-1,2-DIMETHYLCYCLOPENTANE } \\
\hline 2. 33 & 4292 & 7.60 & 1316 \\
\hline 2.47 & 4049 & 7.89 & 1267 \\
\hline 3.00 & 3333 & 8.18 & 1222 \\
\hline 3. 12 & 3205 & 8.37 & 1195 \\
\hline 3.41 & 2933 & 8.62 & 1160 \\
\hline 3.63 & 2755 & 9.04 & 1106 \\
\hline 3. 69 & 2710 & 9.25 & 1081 \\
\hline 4. 11 & 2433 & 9.62 & 1040 \\
\hline 4. 37 & 2288 & 9.82 & 1018 \\
\hline 4. 59 & 2179 & 10.49 & 953 \\
\hline 6.83 & 1464 & 10.55 & 948 \\
\hline 7. 26 & 1377 & 11.28 & 887 \\
\hline 7. 43 & 1346 & 11.53 & 867 \\
\hline \multicolumn{4}{|c|}{ trans-1,2-DIMETHYLCYCLOPENTANE } \\
\hline 2.35 & 4255 & 7.30 & 1370 \\
\hline 2. 46 & 4065 & 7.76 & 1289 \\
\hline 3.12 & 3205 & 8.71 & 1148 \\
\hline 3.40 & 2941 & 9.25 & 1081 \\
\hline 3. 59 & 2786 & 9.94 & 1006 \\
\hline
\end{tabular}

TABLE 2.- Location of infrared absorption bandsContinued

\begin{tabular}{|c|c|c|c|}
\hline $\begin{array}{l}\text { Wave- } \\
\text { length }\end{array}$ & Frequency & $\begin{array}{l}\text { Wave- } \\
\text { length }\end{array}$ & Frequency \\
\hline \multicolumn{4}{|c|}{ trans-1,2-DIMETHYLCYCLOPENTANE } \\
\hline Microns & $c m^{-1}$ & Microns & $\mathrm{cm}^{-1}$ \\
\hline 3.74 & 2674 & 10.17 & 983 \\
\hline 4.07 & 2457 & 10.44 & 958 \\
\hline 4. 36 & 2294 & 10.57 & 946 \\
\hline 4.57 & 2188 & 11.15 & .897 \\
\hline 6.85 & 1460 & 11. 35 & 881 \\
\hline \multicolumn{4}{|c|}{ trans-1,3-DIMETHYLCYCLOPENTANE } \\
\hline & & & \\
\hline 2.34 & 4274 & 6.84 & 1462 \\
\hline 2.46 & 4065 & 7.26 & 1377 \\
\hline 2. 96 & 3378 & 7.38 & 1355 \\
\hline 3.12 & 3205 & 7.57 & 1321 \\
\hline 3.40 & 2941 & 8. 69 & 1151 \\
\hline 3.60 & 2778 & 9.15 & 1093 \\
\hline 3.75 & 2667 & 9.77 & 1024 \\
\hline 4.07 & 2457 & 10.14 & 986 \\
\hline 4. 37 & 2288 & 10.50 & 952 \\
\hline 4. 57 & 2188 & 12.97 & 771 \\
\hline \multicolumn{4}{|c|}{$\begin{array}{l}\text { cis-trans-cis-1,2,4-TRIMETHYL- } \\
\text { CYCLOPENTANE }\end{array}$} \\
\hline 2. 30 & 4348 & 7. 27 & 1376 \\
\hline 2. 33 & 4292 & 7.35 & 1361 \\
\hline 2.45 & 4082 & 7. 46 & 1340 \\
\hline 3.00 & 3333 & 7. 66 & 1305 \\
\hline 3.13 & 3195 & 7.80 & 1282 \\
\hline 3. 43 & 2915 & 8.02 & 1247 \\
\hline 3.63 & 2755 & 8.67 & 1153 \\
\hline 3. 77 & 2653 & 9.26 & 1080 \\
\hline 4.05 & 2469 & 9.77 & 1024 \\
\hline 4. 11 & 2433 & 9.97 & 1003 \\
\hline 4. 66 & 2146 & 10.37 & 964 \\
\hline 4. 79 & 2088 & 10.67 & 937 \\
\hline 4. 98 & 2008 & 11. 38 & 879 \\
\hline 6.86 & 1458 & 13.00 & 769 \\
\hline \multicolumn{4}{|c|}{ CYCLOHEXANE } \\
\hline 2.30 & 4348 & 4. 61 & 2169 \\
\hline 2. 34 & 4274 & 4. 68 & 2137 \\
\hline 2. 38 & 4202 & 4. 84 & 2066 \\
\hline 2. 42 & 4132 & 5.01 & 1996 \\
\hline 2.51 & 3984 & 5.09 & 1965 \\
\hline 2. 90 & 3448 & 5.23 & 1912 \\
\hline 3.00 & 3333 & 5.44 & 1838 \\
\hline 3. 12 & 3205 & 5. 62 & 1779 \\
\hline 3.41 & 2933 & 5. 93 & 1686 \\
\hline 3.52 & 2841 & 6.90 & 1449 \\
\hline 3. 67 & 2725 & 7. 41 & 1350 \\
\hline 3.70 & 2703 & 7.95 & 1258 \\
\hline 3. 77 & 2653 & 8.60 & 1163 \\
\hline 3.93 & 2545 & 9.03 & 1107 \\
\hline 3. 99 & 2506 & 9.61 & 1041 \\
\hline 4. 11 & 2433 & 9.84 & 1016 \\
\hline 4. 29 & 2331 & 11.05 & 905 \\
\hline 4. 42 & 2262 & 11.61 & 861 \\
\hline
\end{tabular}


TABLE 2.-Location of infrared absorption bandsContinued

\begin{tabular}{|c|c|c|c|}
\hline $\begin{array}{l}\text { Wave- } \\
\text { length }\end{array}$ & Frequency & $\begin{array}{l}\text { Wave- } \\
\text { length }\end{array}$ & Frequency \\
\hline \multicolumn{4}{|c|}{ METHYLCYCLOHEXANE } \\
\hline Microns & $\mathrm{cm}^{-1}$ & Microns & $\mathrm{cm}^{-1}$ \\
\hline 2. 32 & 4310 & 4. 80 & 2083 \\
\hline 2.36 & 4237 & 4. 96 & 2016 \\
\hline 2.41 & 4149 & 5. 26 & 1901 \\
\hline 2.45 & 4082 & 5. 56 & 1799 \\
\hline 2.49 & 4016 & 6.86 & 1458 \\
\hline 2.53 & 3953 & 7.27 & 1376 \\
\hline 2.56 & 3907 & 7.33 & 1364 \\
\hline 2.87 & 3484 & 7. 43 & 1346 \\
\hline 2.97 & 3367 & 7.66 & 1305 \\
\hline 3.06 & 3268 & 7. 92 & 1263 \\
\hline 3.14 & 3185 & 8.01 & 1248 \\
\hline 3. 20 & 3125 & 8.57 & 1167 \\
\hline 3.42 & 2924 & 9.02 & 1109 \\
\hline 3.62 & 2762 & 9.15 & 1093 \\
\hline 3.69 & 2710 & 9.43 & 1060 \\
\hline 3. 79 & 2639 & 9.68 & 1033 \\
\hline 4.02 & 2488 & 10.34 & 967 \\
\hline 4.09 & 2445 & 10.99 & 910 \\
\hline 4. 41 & 2268 & 11.47 & 872 \\
\hline 4. 51 & 2217 & 11.86 & 843 \\
\hline 4. 60 & 2174 & 12.76 & 784 \\
\hline 4. 71 & 2123 & 12.96 & 772 \\
\hline \multicolumn{4}{|c|}{ 1,1-DIMETHYLCYCLOHEXANE } \\
\hline 2.30 & 4348 & 5.52 & 1812 \\
\hline 2. 32 & 4310 & 6.85 & 1460 \\
\hline 2.43 & 4115 & 7.22 & 1385 \\
\hline 2.48 & 4032 & 7.32 & 1366 \\
\hline 2.62 & 3817 & 7.55 & 1325 \\
\hline 2. 87 & 3484 & 7. 70 & 1299 \\
\hline 2. 98 & 3356 & 7.80 & 1282 \\
\hline 3.08 & 3247 & 7.91 & 1264 \\
\hline 3.13 & 3195 & 8.02 & 1247 \\
\hline 3.40 & 2941 & 8.40 & 1190 \\
\hline 3.63 & 2755 & 8.50 & 1176 \\
\hline 3.68 & 2717 & 8.69 & 1151 \\
\hline 3.90 & 2564 & 9.11 & 1098 \\
\hline 3.99 & 2506 & 9.25 & 1081 \\
\hline 4.08 & 2451 & 9.53 & 1049 \\
\hline 4. 38 & 2283 & 9.74 & 1027 \\
\hline 4. 51 & 2217 & 10.15 & 985 \\
\hline 4. 56 & 2193 & 10.39 & 962 \\
\hline 4. 71 & 2123 & 10.67 & 937 \\
\hline 4. 92 & 2033 & 10.83 & 923 \\
\hline 4. 99 & 2004 & 10.88 & 919 \\
\hline 5.12 & 1953 & 11.59 & 863 \\
\hline \multirow[t]{2}{*}{5.24} & 1508 & 11.78 & 849 \\
\hline & & 12.81 & 781 \\
\hline \multicolumn{4}{|c|}{ cis-1,2-DIMETHYLCY CLOHEXANE } \\
\hline 2. 29 & 4367 & 7.25 & 1379 \\
\hline 2.31 & 4329 & 7.31 & 1368 \\
\hline 2.44 & 4098 & 7.47 & 1339 \\
\hline 2. 58 & 3876 & 7.58 & 1319 \\
\hline 3.15 & 3175 & 7. 68 & 1302 \\
\hline 3.41 & 2933 & 7.96 & 1256 \\
\hline 3.64 & 2747 & 8.02 & 1247 \\
\hline 3. 70 & 2703 & 8.18 & 1222 \\
\hline 3.79 & 2639 & 8.62 & 1160 \\
\hline 4. 01 & 2494 & 9.14 & 1094 \\
\hline
\end{tabular}

TABLE 2.-Locaiion of infrared absorption bandsContinued

\begin{tabular}{|c|c|c|c|}
\hline $\begin{array}{l}\text { Wave- } \\
\text { length }\end{array}$ & Frequency & $\begin{array}{l}\text { Wave- } \\
\text { length }\end{array}$ & Frequency \\
\hline \multicolumn{4}{|c|}{$c i s-1,2$-DIMETHYLCYCLOHEXANE } \\
\hline Microns & $\mathrm{cm}^{-1}$ & Microns & $\mathrm{cm}^{-1}$ \\
\hline 4. 09 & 2445 & 9. 48 & 1055 \\
\hline 4. 37 & 2288 & 9. 79 & 1021 \\
\hline 4.58 & 2183 & 9. 94 & 1006 \\
\hline 4. 67 & 2141 & 10. 22 & 978 \\
\hline 4. 82 & 2075 & 10.60 & 943 \\
\hline 4. 90 & 2041 & 10.86 & 921 \\
\hline 4. 99 & 2004 & 11. 35 & 881 \\
\hline 5. 19 & 1927 & 11.89 & 841 \\
\hline 5. 39 & 1855 & 12.07 & 829 \\
\hline 5.62 & 1779 & 12. 43 & 805 \\
\hline 6.68 & 1458 & 13. 70 & 730 \\
\hline \multicolumn{4}{|c|}{ trans-1,2-DIMETHYLCYCLOHEXANE } \\
\hline 2.26 & $4425^{\prime}$ & 5.57 & 1795 \\
\hline 2. 30 & 4348 & 6.87 & 1456 \\
\hline 2. 38 & 4202 & 7. 28 & 1374 \\
\hline 2. 85 & 3509 & 7. 46 & 1340 \\
\hline 2. 95 & 3390 & 7. 66 & 1305 \\
\hline 3.04 & 3289 & 7. 97 & 1255 \\
\hline 3. 13 & 3195 & 8. 18 & 1222 \\
\hline 3.42 & 2924 & 8.50 & 1176 \\
\hline 3. 62 & 2762 & 9.03 & 1107 \\
\hline 3. 69 & 2710 & 9. 43 & 1060 \\
\hline 3.80 & 2632 & 9.59 & 1043 \\
\hline 3. 92 & 2551 & 9.95 & 1005 \\
\hline 4. 02 & 2488 & 10. 33 & 968 \\
\hline 4. 12 & 2427 & 10.56 & 948 \\
\hline 4. 34 & 2304 & 10.82 & 924 \\
\hline 4. 44 & 2252 & 11. 31 & 884 \\
\hline 4. 55 & 2198 & 11. 66 & 858 \\
\hline 4. 89 & 2045 & 12.07 & 829 \\
\hline 4. 96 & 2016 & 12. 20 & 820 \\
\hline
\end{tabular}

The absorption spectrum of cis, trans, cis-1,2, 4-trimethylcyclopentane was measured and the results are shown in figure 10 . The $\mathrm{CH}$ vibrations at $3.4 \mu$ and $6.86 \mu$ are about the same in location and intensity as in the other cyclopentanes. The methyl group has a very strong band at $7.27 \mu$. The intensity of the band is greater than that of the dimethylcyclopentanes, but its position is the same. From structural relations this trimethylcyclopentane should have some bands in common with $\operatorname{trans}$-1,3-dimethylcyclopentane. There is a band at $13.0 \mu$ which is present only in these two cyclopentanes. An intense band also occurs at $8.68 \mu$ in the spectrum of both these substances. In like manner the trimethylcyclopentane spectrum and that of trans-1,2-dimethylcyclopentane should have some common features. There are 
bands at 9.24 and $11.38 \mu$ in each spectrum. The bands at $7.78,8.70,9.94$, and $10.38 \mu$ in the spectrum of trans-1,2-dimethylcyclopentane are observed also in the spectrum of cis, trans, cis-1,2, 4-trimethylcyclopentane at approximately the same wavelengths. The other dimethylcyclopentanes do not show as close a relation in their spectra to the trimethylcyclopentane as the two compared here.

The infrared absorption spectra of five cyclohexanes have been measured. In figure 11 is shown the percentage transmission of cyclohexane. Five intense bands are located at wavelengths greater than $7 \mu$ and are characteristic of this molecule. These bands make it possible to readily distinguish cyclohexane from other hydrocarbons. Also, there are a large number of low-intensity bands in the region from 2 to $6 \mu$. This is quite different from the spectrum of cyclopentane in this region. By the presence of so many active infrared bands, it is likely that there is not a high degree of symmetry of this molecule. A structural diagram is shown in figure 4 of cyclohexane and methylcyclohexane. The dimethylcyclohexanes are formed by substituting the methyl groups for the hydrogen atoms at different positions of the molecule. Although in the diagram the carbon atoms are placed in a plane for simplicity of representation, the present indications from various chemical and physical properties point to the carbon atoms not being in a plane but in a chair-like arrangement. That is, the carbons in positions 1, 2, and 3 form a plane, the carbons $1,3,4$, and 6 form another plane, and carbons 4 , 5, and 6, a third plane. As has been mentioned, the 30 combination and harmonic bands, observed in the near infrared with a cell thickness of 0.05 $\mathrm{mm}$, indicate an irregular rather than a planar arrangement of the carbons. The region from 14 to $15 \mu$ was studied with different cell thicknesses up to $1 \mathrm{~mm}$ and no band was found. Because of the decrease in energy due to rock-salt absorption and the presence of the carbon-dioxide absorption band, the accuracy is somewhat less than at shorter wavelengths. A $\mathrm{KBr}$ prism was also used in the instrument, but no absorption band

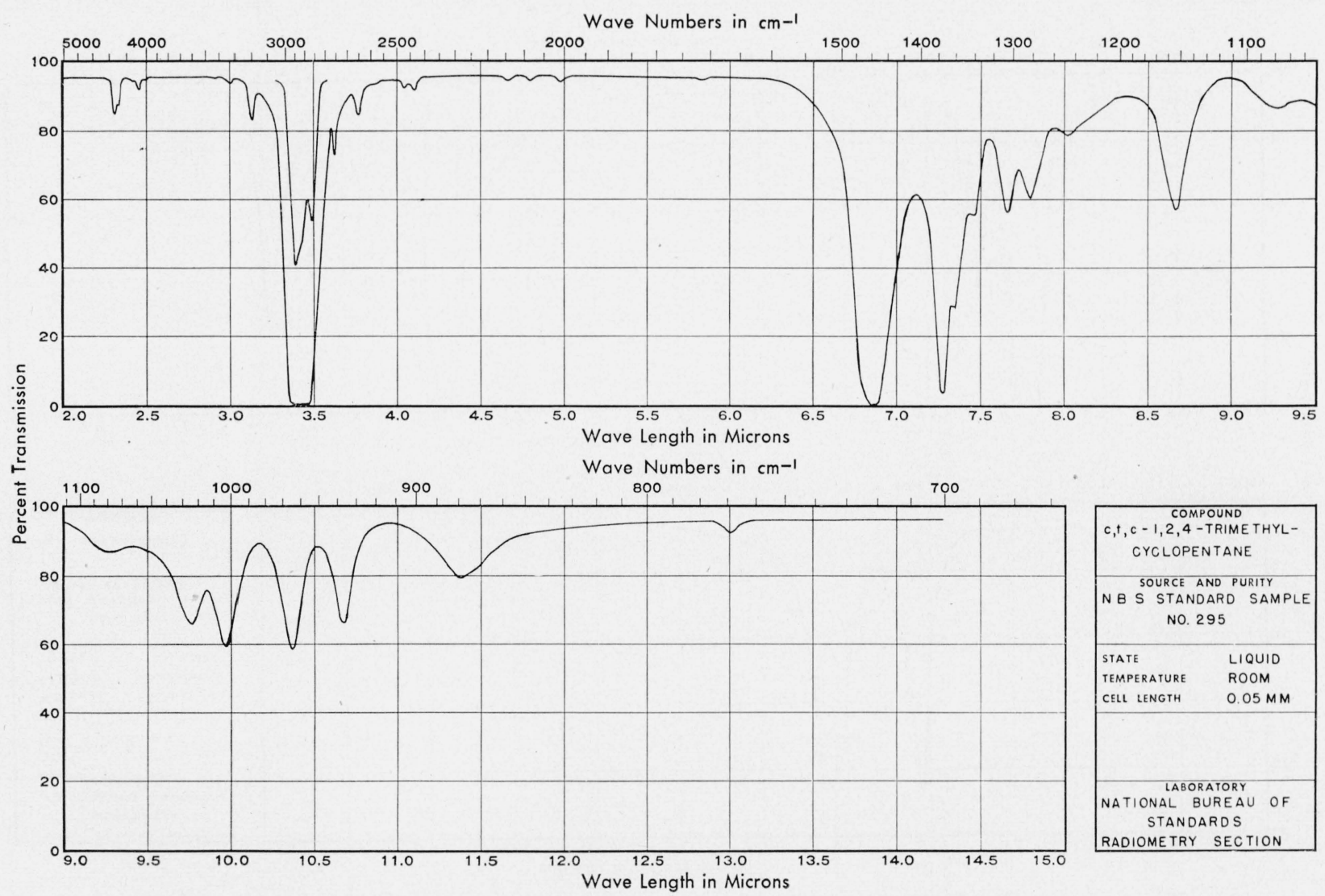

Figure 10.-Percentage transmission of cis, trans, cis-1,2,4-trimethylcyclopentane.

Extra curves at $3.4 \mu$ obtained with cell of $0.004-\mathrm{mm}$ equivalent thickness. 
was found in this region for cyclohexane in the liquid or vapor state. Rasmussen [10] found evidence for a band near $14.6 \mu$. In previous studies Kettering and Sleator [11] found a strong absorption band in this region. The absorption band detected by these investigators may have been due to an impurity in the compound which was studied. However, when the measurements were extended to longer wavelengths two bands were observed at 19.12 and $21.8 \mu$. In the vapor state the $19.12 \mu$ absorption band shows a strong zero branch. There is some doubt as to the type of the band located at $21.8 \mu$. These curves will be shown in another article dealing with the region from 15 to $25 \mu$.

In figure 12 the absorption spectrum of methylcyclohexane is shown. There has been a considerable change from the spectrum of cyclohexane in the region at wavelengths greater than $7 \mu$. In the methylcyclohexane, strong bands are located at $9.16,9.68,10.36,11.00,11.47$, and $11.86 \mu$. The most intense of these bands at $10.36 \mu$ is not present in the spectrum of cyclohexane.
In figures 13,14 , and 15 are shown the absorption spectra of 1,1-dimethylcyclohexane, trans1,2-dimethylcyclohexane, and cis-1,2-dimethylcyclohexane. In the spectrum of 1,1-dimethylcyclohexane there is a double band at $7.3 \mu$. This may be caused by the interaction between the two methyl groups. The double band has much the same appearance as that found in 1,1dimethylcyclopentane and the two minima occur at 7.22 and $7.32 \mu$. The average value of these bands is $7.27 \mu$, which is the position of the band of methylcyclohexane. The absorption bands of cis-1,2-dimethylcyclohexane extend to $13.68 \mu$. Eleven intense bands exist beyond $7.5 \mu$. For use in identification, the two bands at 8.62 and $9.14 \mu$ are the best suited. The other two dimethylcyclohexanes do not have bands in this region. The trans-1,2-dimethylcyclohexane has several intense bands in the region from 10 to $12 \mu$. However, it is best identified by the intense bands at 7.97 and $9.04 \mu$. These two bands readily distinguish it from the spectra of the other cylohexanes that have been measured.

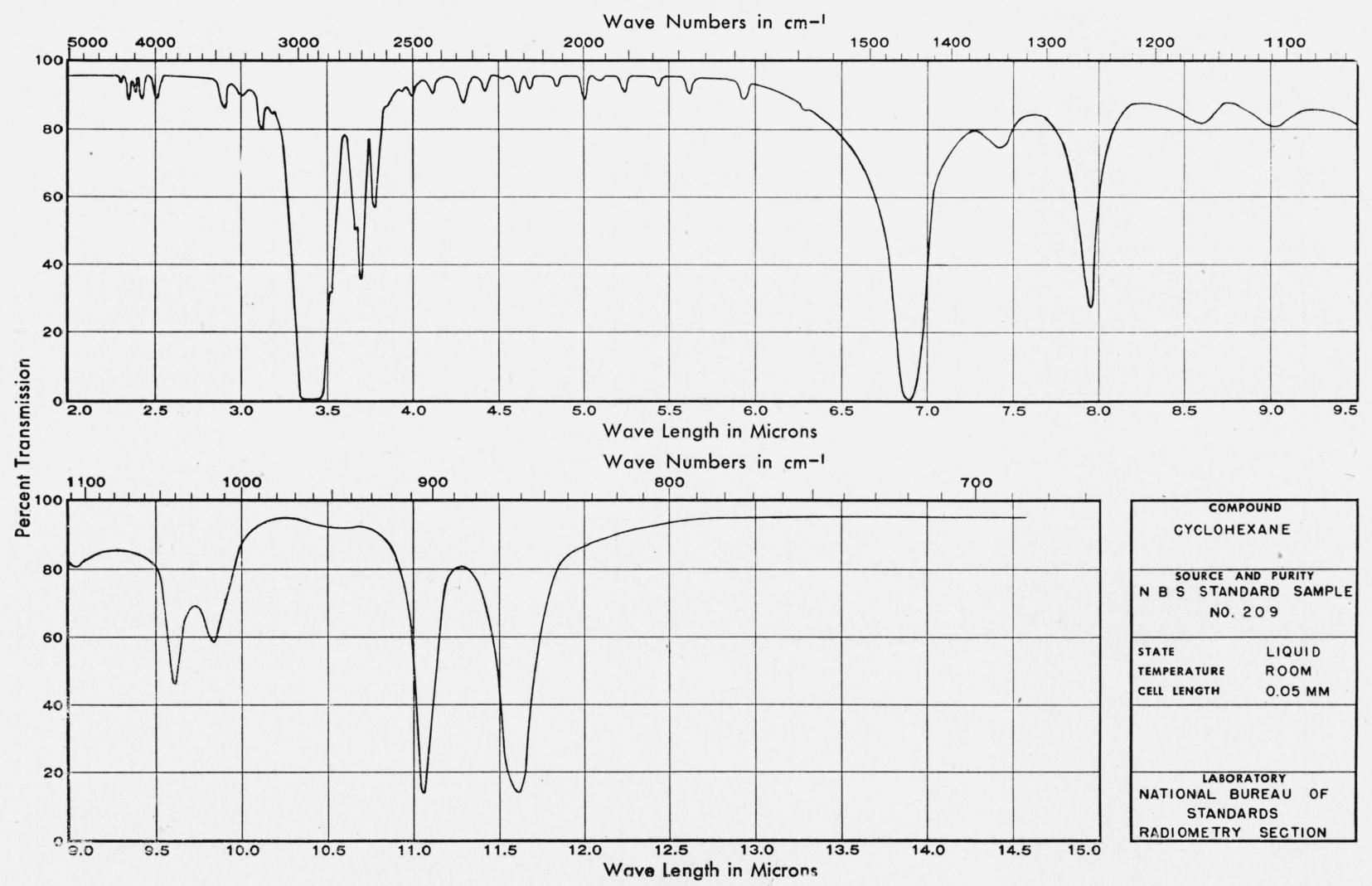

Figure 11.-Percentage transmission of cyclohexane. 
The samples of the 12 compounds whose spectra are reported here are materials of high purity. The spectra should be of value in looking for impurities in compounds of this nature and also in identifying these compounds as impurities in other substances. The wavelengths given in table 2 are of good accuracy for results obtained with a prism spectrometer. Some of these substances have been measured on other spectrometers. The results shown here check well with those obtained on instruments containing larger prisms and having higher resolution. A comparison of our measurements with results obtained at the
Texas Oil Co. laboratory at Beacon, N. Y., reveals that the location of the majority of the bands of a substance check within $0.01 \mu$, and scarcely any bands differ by more than $0.03 \mu$. Instances of greater discrepancy occur only in the case of broad bands, that do not have a well-defined minimum.

The absorption spectra may be of value to other laboratories as a secondary check on the calibration of their infrared spectrometer. This work is to be continued on other hydrocarbons as they become available in a high degree of purity.

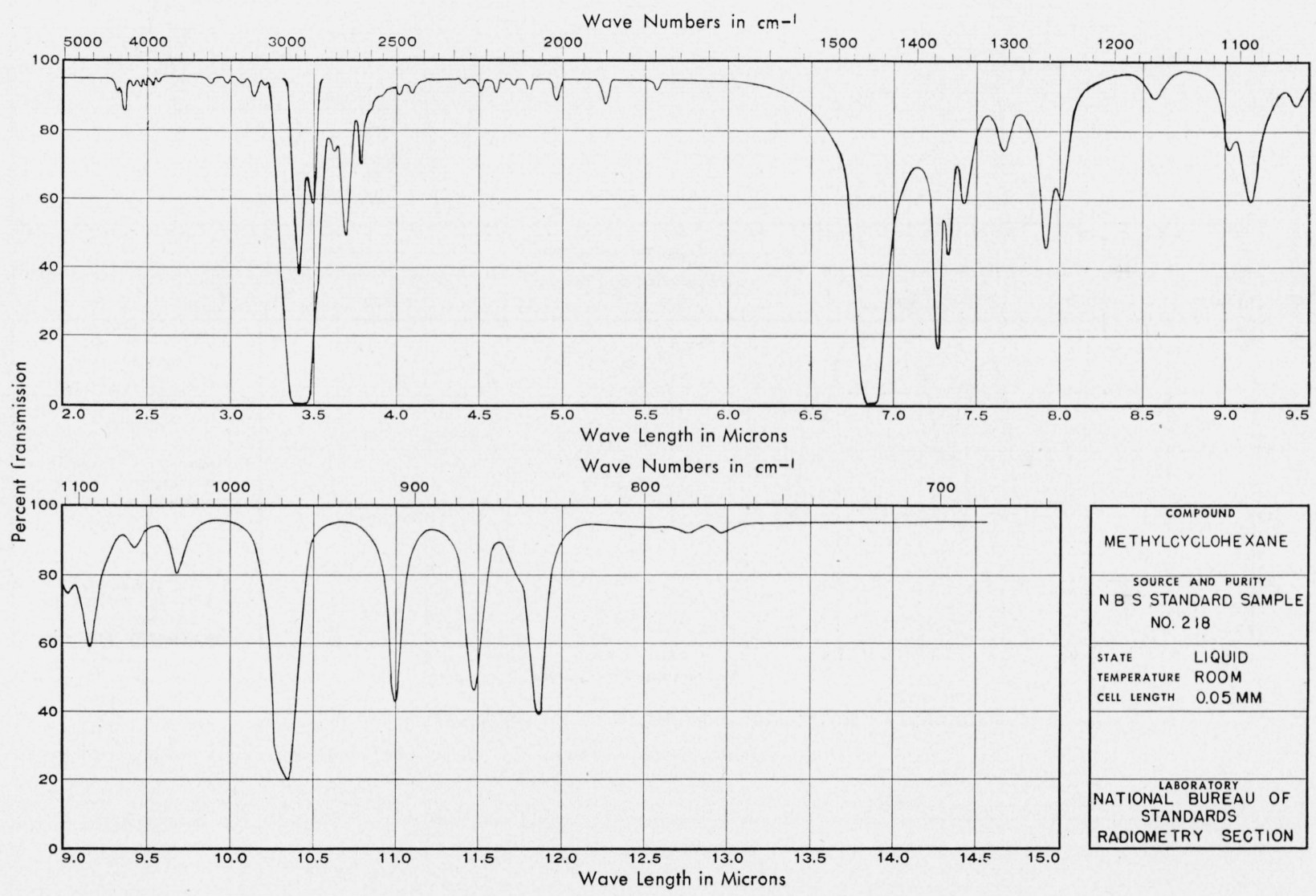

Figure 12.-Percentage transmission of methylcyclohexane.

Extra curve at $3.4 \mu$ obtained with cell of $0.004-\mathrm{mm}$ equivalent thickness. 


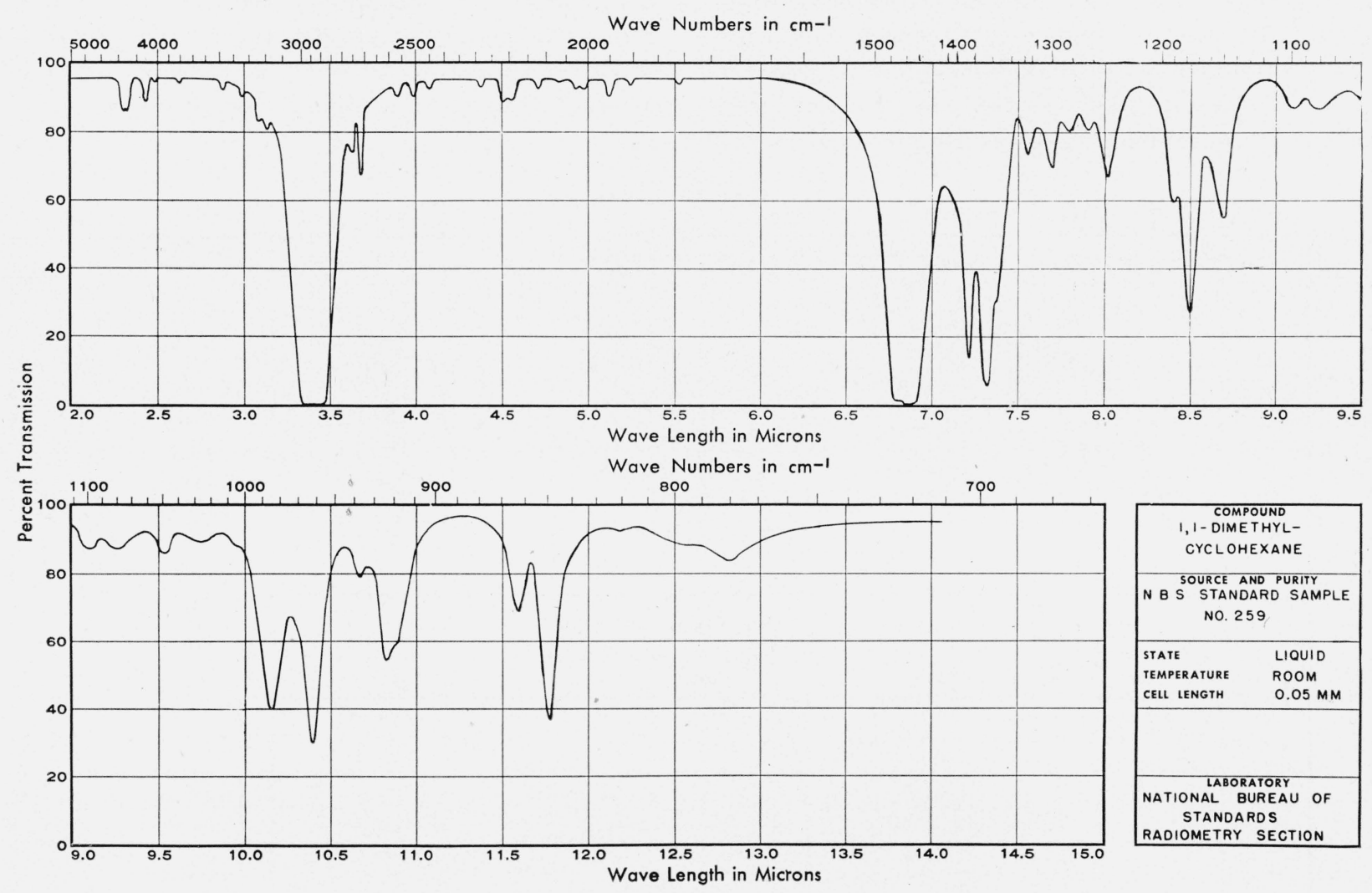

FIGURE 13.-Percentage transmission of 1,1-dimethylcyclohexane. 


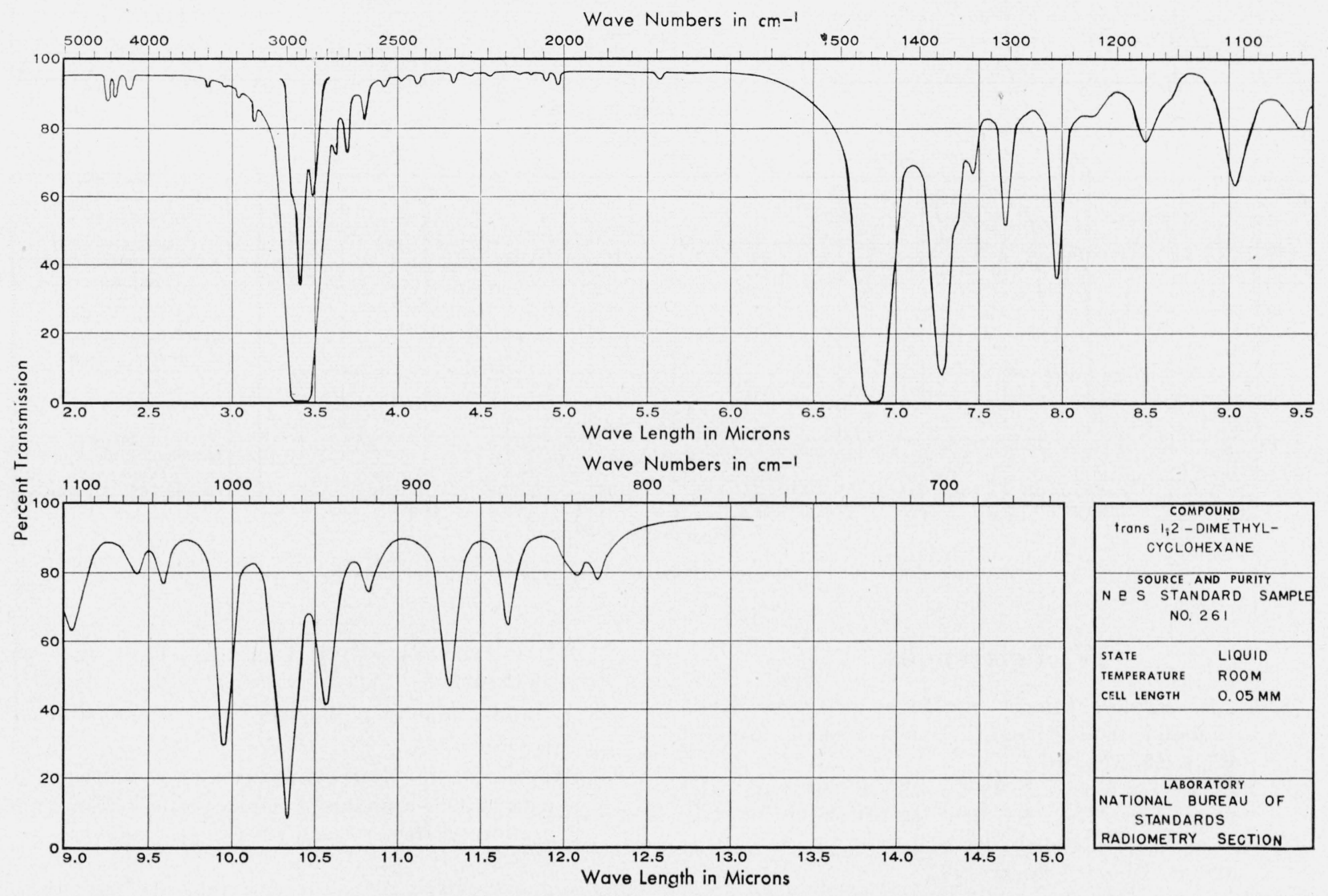

Figure 14.-Percentage transmission of trans-1,2-dimethylcyclohexane.

The extra curve at 3. $4 \mu$ was for a cell of 0.004-equivalent thickness. 


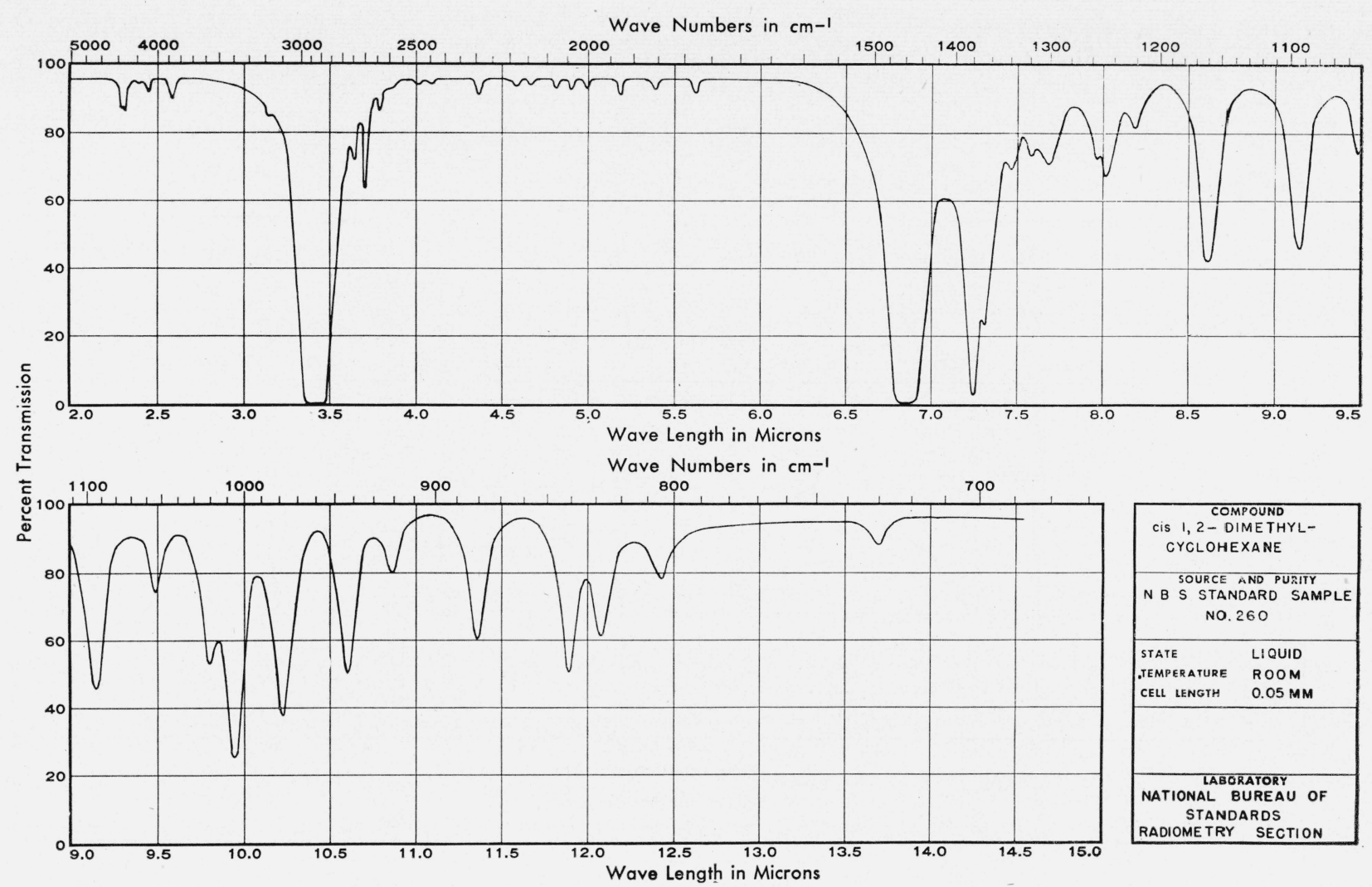

FIGURE 15.-Percentage transmission of cis-1,2-dimethylcyclohexane.

\section{References}

[1] R. B. Barnes, Robert S. McDonald, Van Zandt Williams, and Richard F. Kinnaird, J. Applied Phys. 16, 77 (1945).

[2] Max D. Liston, C. E. Quinn, W. E. Sargeant, and G. G. Scott, Rev. Sci. Instr. 5, 194 (1946).

[3] H. Kayser, Handbuch der Spectroscopie 8, part 1, 380 (S. Hirzel, Leipzig, 1932).

[4] H. Kayser, Handbuch der Spectroscopie $\boldsymbol{7}, 648$ (S. Hirzel, Leipzig, 1934).

[5] W. W. Sleator, Astrophys. J. 48, 125 (1918); E. K. Plyler and W. W. Sleator, Phys. Rev. 37, 1493 (1931).

[6] P. E. Martin and E. F. Barker, Phys. Rev. 41, 291 (1932).
[7] D. M. Dennison and J. D. Hardy, Phys. Rev. 39, 938 (1932).

[8] A. Borden and E. F. Barker, J. Chem. Phys. 6, 553 (1938).

[9] Supplement to National Bureau of Standards Circular C398, Standard Samples Issued or in Preparation by the National Bureau of Standards, p. 6 (1946).

[10] Robert S. Rasmussen, J. Chem. Phys. 11, 249 (1943).

[11] C. F. Kettering and W. W. Sleator, Physics 4, 39 (1933).

Washington, September 5, 1946. 